\title{
Acetylcholine Receptor Expression in Developing Chick Ciliary Ganglion Neurons
}

\author{
Michele H. Jacob \\ Worcester Foundation for Experimental Biology, Shrewsbury, Massachusetts 01545
}

Little is known about the levels of nicotinic ACh receptors (AChRs) in neurons prior to innervation and whether the distribution and number of receptors change in response to innervation. In the present study, AChR levels were examined in developing chick ciliary ganglion neurons in situ at stages preceding and during early and late phases of synaptogenesis. AChRs were localized in surface and intracellular pools of intact and saponin-permeabilized ganglionic neurons, respectively, by using a highly sensitive immunocytochemical approach that included the binding of an antiAChR monoclonal antibody (mAb) followed by a biotinylated secondary antibody and an avidin-biotinylated HRP complex.

At older stages of development, embryonic day (ED) 7 7.5 and ED 11, when all of the neurons are known to be receiving synaptic contacts, AChRs were present in both internal and surface pools. Within the neurons, AChRs were associated with organelles that function in the biosynthesis, processing, and transport of integral plasma membrane proteins. On the surface of the neurons, AChRs were predominantly localized in the specialized postsynaptic membrane, with low levels of AChRs being present in extrasynaptic regions.

The earliest stage at which synapses could be detected in the ganglion was ED 4.5. Synapses were detected by light microscopic immunocytochemical labeling with anti-SV2, an mAb to a synaptic vesicle protein, and by ultrastructural analysis. At this stage, most of the neurons were not labeled by the anti-AChR mAb, while a few neurons had dense deposits of reaction product on the rough endoplasmic reticulum and portions of the nuclear envelope. Low levels of reaction product were also found on the surface of a small number of neurons, being localized predominantly on the specialized postsynaptic membrane of the few immature synapses present. Occasionally, small patches of labeling were observed in extrasynaptic regions. In contrast, little

\footnotetext{
Received Aug. 31, 1990; revised Jan. 9, 1991; accepted Jan. 11, 1991.

I thank Dr. Justin Fallon and Dr. Lynn Arenella for valuable comments on the manuscript. I thank Dr. Darwin Berg (University of California, San Diego) for generously providing the hybridoma cell line producing the monoclonal antibody $\mathrm{mAb} 35$, which was originally isolated by Dr. Jon Lindstrom and colleagues (Salk Institute), and Dr. Kathy Buckley (Harvard Medical School) and Dr. Regis Kelly (University of California, San Francisco) for kindly providing the anti-SV2 monoclonal antibody. I also thank Tracie Payne for help with the light microscopic immunocytochemistry. Cynthia Kane and Jeanne Oliva provided expert technical assistance. Grant support was provided by NIH Grant NS 21725 and by the Pfeiffer Foundation.

Correspondence should be addressed to Michele Jacob, Worcester Foundation for Experimental Biology, 222 Maple Avenue, Shrewsbury, MA 01545.

Copyright (C) 1991 Society for Neuroscience $0270-6474 / 91 / 111701-12 \$ 03.00 / 0$
}

internal and no surface anti-AChR immunolabeling was detected in ciliary ganglion neurons prior to innervation, at ED 3.5-4. The finding of a large increase in both internal and surface AChR levels in the neurons at the time of innervation suggests that signals from the presynaptic input play an important role in the induction of AChR expression in neurons.

Motor innervation is known to influence the number, type, and distribution of nicotinic $A C h$ receptors (AChRs) in vertebrate skeletal muscle (Fambrough, 1979; Salpeter, 1987; Schuetze and Role, 1987; Brehm and Henderson, 1988; Gu and Hall, 1988). Less is known regarding the role of innervation in the regulation of AChR number, type, and distribution in neurons, particularly at the early developmental stages of initial synapse formation.

In mature neurons, signals from presynaptic inputs regulate AChR number, AChR mRNA levels, and the kinetics of AChR channels expressed on the neuronal surface. Denervation of a subpopulation of adult bullfrog sympathetic ganglion cells and subsequent reinnervation of the cells with preganglionic fibers having a different conduction velocity result in a change in the channel kinetics of AChRs expressed on the cell surface (Marshall, 1985). Further, unilateral preganglionic denervation of parasympathetic ciliary ganglia in newly hatched chicks results in a threefold decline in both $\mathrm{AChR}$ and $\mathrm{AChR} \alpha 3$-subunit mRNA levels after $10 \mathrm{~d}$ as compared to the amounts present in unoperated contralateral ganglia from the same chicks (Jacob and Berg, 1987; Boyd et al., 1988). The reduction in AChR levels involves the selective loss of receptors from the internal pool of AChRs (Jacob and Berg, 1988). Normally, approximately two-thirds of the total AChRs are intracellular at this stage of development and are associated with organelles that function in the biosynthesis, processing, and transport of integral plasma membrane proteins (Jacob et al., 1986; Stollberg and Berg, 1987; Jacob and Berg, 1988). The surface population of AChRs, which is predominantly localized in the specialized postsynaptic membrane (Jacob et al., 1984, 1986), is not detectably changed after denervation (Jacob and Berg, 1988; McEachern et al., 1989). This finding is consistent with the observation of no change in the ACh response of denervated adult frog sympathetic neurons (Dunn and Marshall, 1985). In contrast, denervation of adult frog parasympathetic cardiac ganglion neurons causes a change in the distribution and a decrease in the number of surface AChRs (Sargent and Pang, 1988; Sargent and Bryan, 1989), as well as an increase in ACh sensitivity by an as yet undetermined mechanism (Kuffler et al., 1971; Dennis and Sargent, 1979). Altogether, the findings demonstrate that presynaptic input influences $A C h R$ channel kinetics and 
the maintenance of AChR levels in mature neurons, and that the latter effect is exerted, at least in part, by the regulation of AChR mRNA levels.

Little is known about AChR levels in developing neurons prior to innervation and whether significant changes occur in the number and distribution of AChRs at the time of innervation. Recent electrophysiological studies have demonstrated that innervation influences the ACh sensitivity of developing neurons. Innervation of embryonic day (ED) 9-10 chick sympathetic ganglion neurons in culture by the appropriate preganglionic tissue, the dorsal spinal cord, results in a 10-fold increase in ACh sensitivity as compared to the levels on neurons grown alone (Role, 1988). Similarly, the ACh sensitivity of dissociated embryonic chick sympathetic and parasympathetic ciliary ganglion neurons increases fourfold and eightfold from ED 10 to ED 17 and from ED 8 to ED 16, respectively, representing in both cases a developmental period of continued synapse formation and maturation (Margiotta and Gurantz, 1989; Moss et al., 1989). In both neuron populations, the increased ACh sensitivity was shown to be due, at least in part, to changes in the AChR single-channel properties. The changes include increases in the apparent mean open time and in the relative abundance of the large-conductance channels and, in the case of the sympathetic neurons, increases in the conductances of two smaller channel classes and the appearance of a new large-conductance channel class (Margiotta and Gurantz, 1989; Moss et al., 1989). The numbers of both total and surface AChRs increase as well in chick ciliary ganglion neurons developing from ED 8 to ED 18 (Smith et al., 1985; Margiotta and Gurantz, 1989). The highcst levels of AChRs arc reached between ED 12 and 18, when synapses are maturing and being consolidated on the neurons. These findings suggest that signals from presynaptic inputs play a role in the induction of $\mathrm{AChR}$ expression in neurons. In all of these studies, however, the neurons were already innervated to some extent even at the earliest developmental stages examined. ED 9-10 chick sympathetic ganglion neurons have a small number of synapses present (Hruschak et al., 1982). ED 8 chick ciliary ganglion neurons all receive chemical synaptic transmission (Landmesser and Pilar, 1972). The clectrophysiological studies are also limited by the fact that only a proportion of the surface receptors are functional; silent receptors exist on the neuron surface (Margiotta et al., 1987a,b; Margiotta and Gurantz, 1989).

To examine the distribution of AChRs in neurons prior to innervation and to determine whether synapse formation influences AChK levels in neurons, the ultrastructural distribution of AChRs was determined in chick ciliary ganglion neurons in situ before and after the establishment of innervation. Monoclonal antibody (mAb) 35, an mAb raised against Electrophorus electric organ AChRs (Tzartos et al., 1981) that cross-reacts with neuronal AChRs (Jacob et al., 1984; Smith et al., 1985, 1986; Halvorsen and Berg, 1987), was used together with a biotinylated secondary antibody and an avidin-biotinylated HRP complex to localize AChRs in the surface and the intracellular pools of intact and saponin-permeabilized ganglionic neurons, respectively. Ciliary ganglia from ED $3.5-4$ to ED 11 chicks were examined to compare the distribution of AChRs in the surface and internal pools to the temporal and spatial pattern of synapse formation on the neurons. In this study, it was found that few AChRs are present in surface or internal pools of the neurons prior to innervation, and that substantial levels of AChRs appear in both pools during the period of innervation.

\section{Materials and Methods}

Embryos and staging. White Leghorn cmbryonated chick eggs were obtained from Spafas (Norwich, CT) and maintained at $37^{\circ} \mathrm{C}$ in a humidified incubator until use. Embryos were staged according to the Hamburger and Hamilton (1951) classification scheme. The days of embryonic development are based on the stage $(\mathrm{St})$ rather than the actual days of incubation. The developmental stages investigated in this study include ED 3.5-4 (St 22-23), ED 4.5 (St 24), ED 5-6 (St 26-28), ED 7-8 (St 31-34), ED 11 (St 37), and ED 12-13 (St 38-39).

Light microscopy. The presence of AChRs in embryonic chick ciliary ganglion neurons at early stages of development was examined initially by indirect immunohistochemical staining at the light microscopic level. Either rhodamine-conjugated avidin or an avidin-biotinylated HRP macromolecular complex was used to detect AChRs in ganglionic sections. The labeling was carried out as previously described, with a few modifications (Jacob et al., 1986). Briefly, ciliary ganglia at selected developmental stages ranging from ED 4 to ED 13 were dissected, lightly fixed with $0.5 \%$ paraformaldehyde for $0.5-1 \mathrm{hr}$, rinsed, infused with 2.3 $M$ sucrose, embedded in optimum-cutting-temperature (OCT) compound, frozen, and cut into $8-\mu \mathrm{m}$ sections with a cryostat at $-18^{\circ} \mathrm{C}$ The sections were mounted on poly-L-lysine coated glass slides, air dried, and stored at $4^{\circ} \mathrm{C}$ overnight. The next day the sections were rinsed, incubated with an anti-AChR mAb, mAb 35, at $0.1 \mu \mathrm{M}$ for $1 \mathrm{hr}$, rinsed, incubated with $0.1 \mu \mathrm{m}$ biotinylated rabbit anti-rat antibody for $0.5-1$ $\mathrm{hr}$, rinsed again, and then incubated with $0.1 \mu \mathrm{M}$ rhodamine-conjugated avidin for $0.5-1 \mathrm{hr}$, followed by a final series of rinses. After partial drying and mounting in glycerol, labeled sections were viewed with a Zeiss Axioskop fluorescence microscope.

Alternatively, some sections were incubated with an avidin DH-biotinylated HRP H macromolecular complex (Vectastain Elite ABC kit, Vector Labs) in PBS following incubation with $\mathrm{mAb} 35$ and the biotinylated secondary antibody, using the manufacturer's recommended dilutions for $30-40 \mathrm{~min}$ at room temperature. The sections were then rinsed three times for 5 min each with PBS, postfixed with $1 \%$ glutaraldehyde in PBS for 10 min, rinsed once with PBS and once with 0.05 M Tris- $\mathrm{HCl}$ buffer (pH 7.4) containing $7.5 \%$ sucrose for $5 \mathrm{~min}$ each, and incubated with $0.05 \% 3,3^{\prime}$-diaminobenzidine in Tris- $\mathrm{HCl}$ buffer containing sucrose plus $0.03 \%$ hydrogen peroxide for $20-30 \mathrm{~min}$ in the dark. The sections were rinsed twice for $5 \mathrm{~min}$ each with Tris- $\mathrm{HCl}$ buffer containing sucrose, partially dried, mounted in glycerol, and viewed by bright-field microscopy.

Indirect immunohistochemical labeling was also used to look for the presence of synaptic vesicles in the developing ganglia. Synaptic vesicles were detected in the ganglionic sections by using an mAb to the transmembrane glycoprotein SV2 (Buckley and Kelly, 1985) at a 1:50 dilution and a biotinylated horse anti-mouse antibody at $0.1 \mu \mathrm{M}$. Most of the sections were labeled with the biotinylated HRP macromolecular complex because it resulted in less nonspecific background labeling as compared to rhodamine-conjugated avidin. Ganglia were processed as described above.

Electron microscopy. Ultrastructural techniques were used to examine the distribution of both surface and internal AChRs in the developing neurons. For labeling of intracellular AChRs, ganglia were processed as previously described except that an avidin DH-biotinylated HRP H complex was used to visualize bound mAb 35 (Jacob et al., 1986). Briefly, ciliary ganglia from ED 4.5, ED 7-7.5, and ED 11 chicks were lightly fixed, detergent-permeabilized with saponin to gain access to internal sites, incubated with $\mathrm{mAb} 35$ for $2.5 \mathrm{hr}$, rinsed, incubated with biotinylated rabbit anti-rat antibody in PBS for $2.5 \mathrm{hr}$, rinsed, incubated with avidin-biotinylated HRP complex in PBS for $2.5 \mathrm{hr}$, rinsed, fixed, reacted for peroxidase activity, and processed for electron microscopy. For labeling of surface AChRs, ganglia were processed as previously described with the following modifications (Jacob and Berg, 1988). Briefly, ganglia were dissected into avian Ringer's solution, incubated without fixation in $\mathrm{mAb} 35$, rinsed, fixed in freshly prepared $1.0 \%$ paraformaldehyde in $0.02 \mathrm{M}$ sodium phosphate buffer ( $\mathrm{pH} 7.2$ ) containing $0.06 \mathrm{M}$ sucrose for $0.5 \mathrm{hr}$, rinsed twice for $10 \mathrm{~min}$ each in $0.05 \mathrm{M}$ ammonium chloride in PBS, rinsed once in $0.02 \mathrm{M}$ sodium phosphate buffer containing $0.06 \mathrm{M}$ sucrose, and incubated with biotinylated rabbit anti-rat antibody. Ganglia were then processed as described above for ganglia being labeled for internal AChRs. For both procedures, the older ganglia were cut into halves to facilitate reagent penetration, and normal rabbit serum $(10 \%, v / v)$ was added to the buffer before, during, and after $\mathrm{mAb}$ 35 incubation. 
These methods were modified slightly for the labeling of AChRs in ED 3.5-4 ganglia due to the long period of time required to dissect the ganglia at this stage of development. The changes included the use of PBS in place of avian Ringer's because the Ringer's solution requires aeration to maintain the desired $\mathrm{pH}$, fixation of all ganglia in $0.75 \%$ paraformaldehyde in $0.02 \mathrm{M}$ sodium phosphate buffer containing 0.06 $M$ sucrose for $1 \mathrm{hr}$, and rinsing with ammonium chloride in PBS and sodium phosphate buffer, all prior to $\mathrm{mAb} 35$ incubation. For the labeling of surface AChRs, ganglia were then incubated with mAb 35 overnight at $4^{\circ} \mathrm{C}$. For internal AChR labeling, ganglia were permeabilized with saponin, rinsed, and incubated with $\mathrm{mAb} 35$ overnight at $4^{\circ} \mathrm{C}$. Ciliary ganglia from ED 16 chicks were also processed using these modifications to establish that the ability to detect AChRs in the surface and intracellular pools of the neurons is not influenced by the changes in the methods necessary for the processing of ED 3.5-4 ganglia.

In all cases, thin sections of the labeled ganglia were stained with aqueous uranyl acetate and examined with a Philips 301 electron microscope.

Materials. MAb 35 was purified as previously described (Smith et al., 1985) from the medium of a hybridoma cell line initially isolated by Dr. Jon Lindstrom and colleagues (Salk Institute, San Diego, CA). The anti-SV $2 \mathrm{mAb}$ was generously provided by Dr. Kathy Buckley (Harvard Medical School) and Dr. Regis Kelly (University of California, San Francisco, CA). Biotinylated rabbit anti-rat IgG, biotinylated horse antimouse IgG, avidin DH-biotinylated HRP H complex (Vectastain Elite $\mathrm{ABC}$ kit), and rhodamine-conjugated avidin were purchased from Vector Labs.

\section{Results}

\section{Light microscopic analysis}

The expression of AChRs in developing chick ciliary ganglion neurons was first examined at the light microscopic level and compared to the presence of synaptic vesicle protein immunoreactivity in the ganglionic sections. AChRs and synaptic vesicle protein were detected in frozen scctions of ciliary ganglia ranging from ED 4 to ED 13 by the binding of $\mathrm{mAb} 35$ and anti-SV2 $\mathrm{mAb}$, respectively. The bound $\mathrm{mAbs}$ were detected by incubation with the appropriate biotinylated secondary antibody followed by rhodamine-conjugated avidin or an avidinbiotinylated HRP complex. At the earlier developmental stages, nonspecific background staining was reduced when the avidinbiotinylated HRP complex was used, particularly in sections treated with anti-SV $2 \mathrm{mAb}$ followed by biotinylated anti-mouse antibody.

Ciliary ganglion neurons from older embryos, ED 16, have previously been shown to have well-differentiated synaptic contacts and to contain large amounts of receptor in both surface and internal pools (Landmesser and Pilar, 1972; Jacob et al., 1984, 1986; Smith et al., 1985; Stollberg and Berg, 1987). Similarly, anti-AChR and anti-SV2 immunolabeling was observed in sections of ED 12 and 13 ganglia (Fig. la,b). Intense anti$\mathrm{AChR} \mathrm{mAb}$ labeling filled the neuronal somas, with only the nuclei being unlabeled, resembling the pattern of staining previously observed in ED 16 neurons (Jacob et al., 1986). AChR labeling was present in $96 \%$ of the ED 12-13 neurons (Table 1). No other structures in the ganglion were labeled. In ED 12 ganglionic sections immunolabeled with anti-SV2 $\mathrm{mAb}$, a thin patch of staining was present on a portion of the surface of $83 \%$ of the neurons. With the exception of the earliest stages examined, the detection of a distinct area of synaptic vesicle protein labeling immediately adjacent to a portion of the neuron surface was taken to represent the presence of presynaptic terminals on the neurons. By ED 8 (St 33.5), all of the neurons are receiving chemical synaptic transmission (Landmesser and $\mathrm{Pi}-$ lar, 1972). The absence of anti-SV2 immunolabeling on the surface of a small number of ED 12 neurons is likely due to the
Table 1. AChR and synaptic vesicle protein immunoreactivity in developing ciliary ganglion neurons

\begin{tabular}{lll} 
Ciliary ganglion age & $\begin{array}{l}\text { Proportion of } \\
\text { AChR-labeled } \\
\text { neurons }\end{array}$ & $\begin{array}{l}\text { Proportion of } \\
\text { anti-SV2-labeled } \\
\text { neurons }\end{array}$ \\
\hline ED 12-13 (St 38-39) & $96 \pm 1 \%(30 ; 3556)$ & $83 \pm 1 \%(27 ; 1914)$ \\
ED 7-8 (St 31-34) & $88 \pm 2 \%(9 ; 1217)$ & $75 \pm 2 \%(25 ; 5385)$ \\
ED 5-6 (St 26-28) & $53 \pm 3 \%(33 ; 4630)$ & $47 \pm 4 \%(10 ; 2750)$ \\
ED 4.5-5 (St 24-25) & $30 \pm 3 \%(10 ; 989)$ & $56 \pm 3 \%(19 ; 4783)$ \\
ED 4 (St 23) & $0 \%(12 ;$ ND) & $0 \%(16 ;$ ND)
\end{tabular}

The proportion of neurons with anti-AChR and anti-SV2 immunolabeling was determined by indirect immunocytochemical labeling of cryostat sections. The values represent the mean $\pm S E$; the numbers in parentheses indicate the number of ganglionic sections examined and the total number of neurons from all the sections combined, respectively.

fact that not all presynaptic terminals are visible in a single plane of section through the ganglion. At ED 7-8, anti-AChR and anti-SV2 immunolabeling was present in $88 \%$ and $75 \%$ of the ganglionic neurons, respectively, with the same general staining pattern as seen at the older stages (Fig. $1 c, d$ ). At ED 5-6, $53 \%$ of the neuronal somas were stained following anti-AChR immunolabeling, and some of the neurons were heavily labeled (Fig. 1e). About one-half of the neurons had patches of antiSV2 staining on a portion of their surface as well (Fig. 1f). ED 5 (St 26.5) is the earliest time at which synapses have previously been detected in the ganglion (Landmesser and Pilar, 1972). At ED 4.5-5, the thin rim of cytoplasm surrounding the nucleus contained anti-AChR labeling in $30 \%$ of the neurons (Fig. $2 a$ ). At ED 4.5, anti-SV2 staining was present in structures immediately adjacent to a part of the surface of $56 \%$ of the neurons (Fig. 2b). It is not known, however, what proportion of the antiSV2-stained structures represent immature synapses at this early developmental stage. It is likely that some of the labeled structures are growth cones emanating from neurons of the preganglionic Edinger-Westphal (accessory oculomotor) nucleus, as well as from ciliary ganglion neurons themselves, which are beginning to extend axons at this stage (Landmesser and Pilar, 1978). Using ultrastructural techniques, it was established that at least some of the anti-SV2 staining represents the presence of morphologically specialized, immature synapses on the surface of a small number of neurons at this stage. Further, antiSV2 immunolabeling was present in all 38 ganglionic sections examined at ED 4.5-5, and the labeled structures appeared to be scattered throughout the cross-sectional area of the ganglion. In contrast, at ED 4, no AChR and no synaptic vesicle protein immunoreactivity was detected in 12 and 16 ganglionic sections, respectively (Fig. $2 c, d$ ).

\section{Ultrastructural distribution in developing neurons}

Ultrastructural analysis of AChR distribution was carried out to establish the presence of AChRs in both surface and intracellular pools of the developing neurons relative to the time and site of synapse formation. Ciliary ganglia from ED 3.5-4, ED 4.5, ED 7-7.5, and ED 11 chicks were studied in order to include stages preceding and during early and late phases of synaptogenesis. When synaptic contacts were identified on the neuron surface, both synaptic and extrasynaptic regions were analyzed for the presence of AChRs. Freshly dissected, unfixed or lightly fixed ganglia were incubated with $\mathrm{mAb} 35$ for the labeling of surface AChRs, while lightly fixed ganglia were permeabilized 

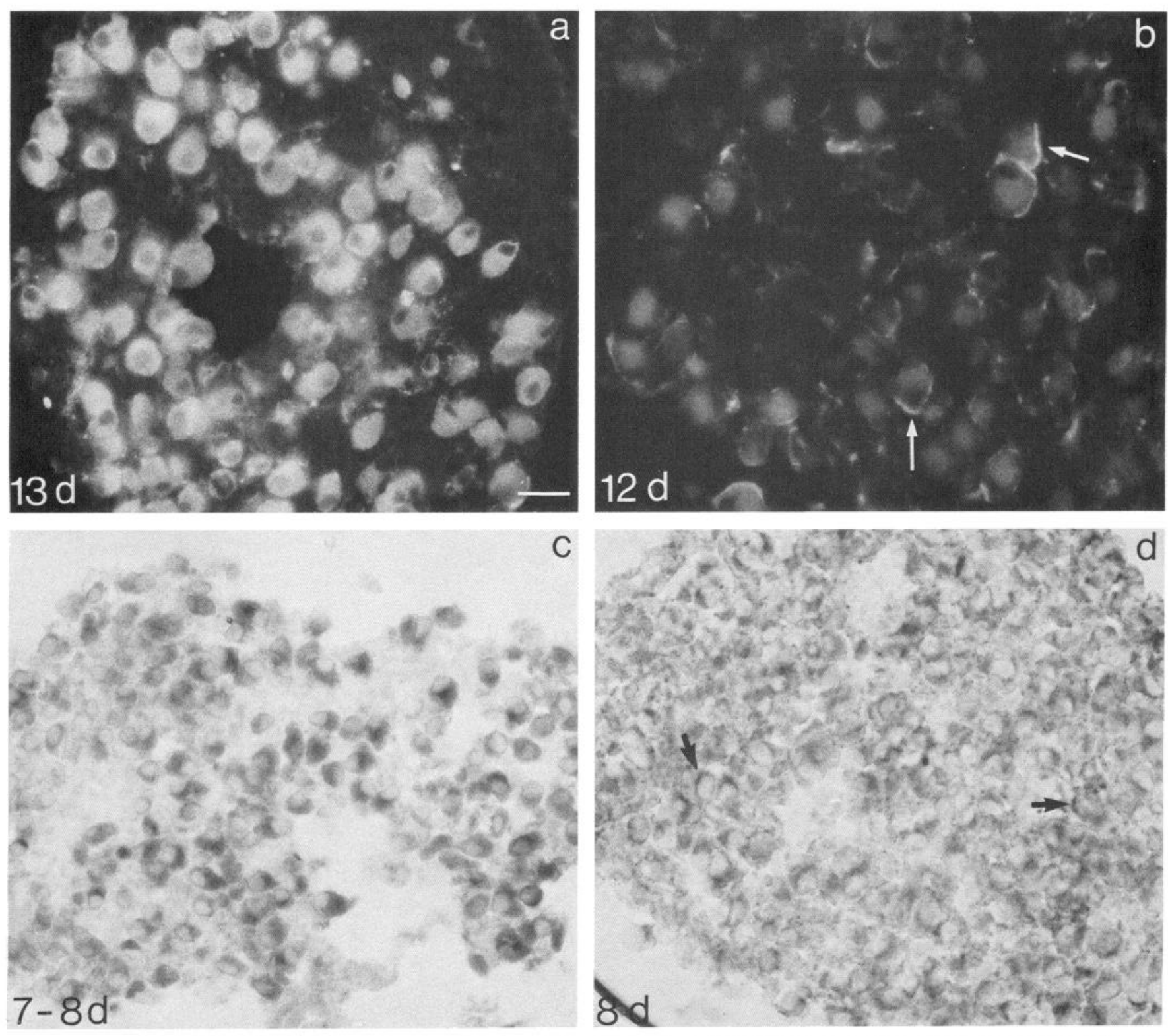

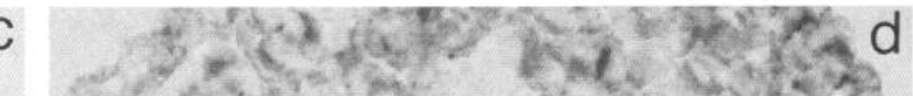

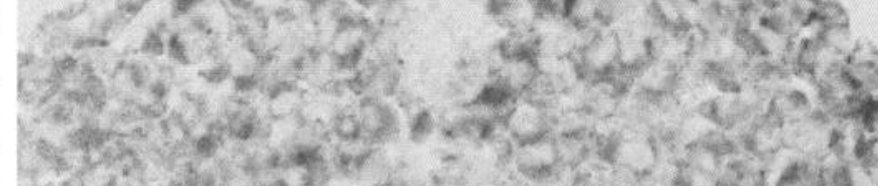

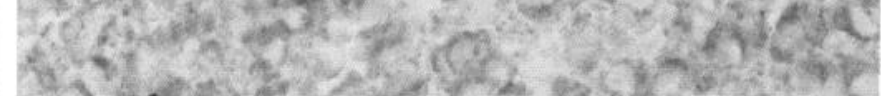

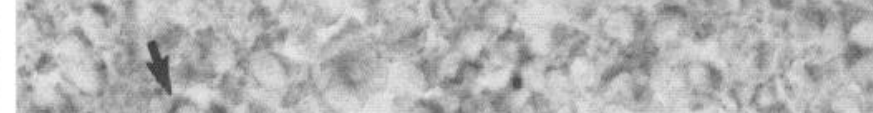

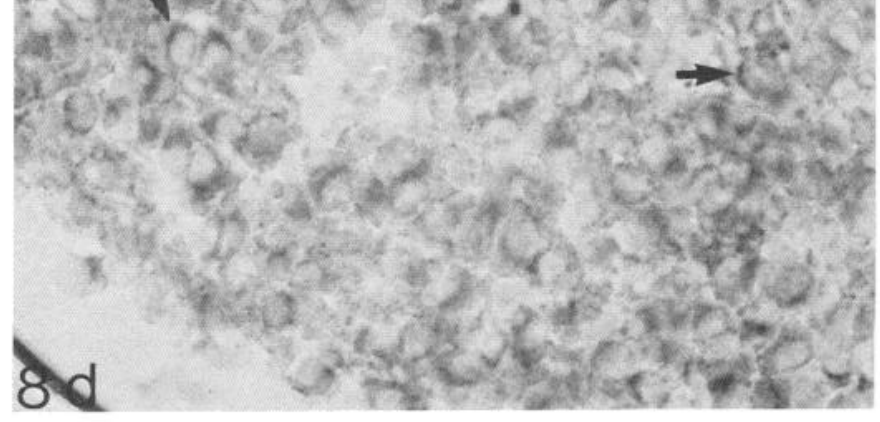

e

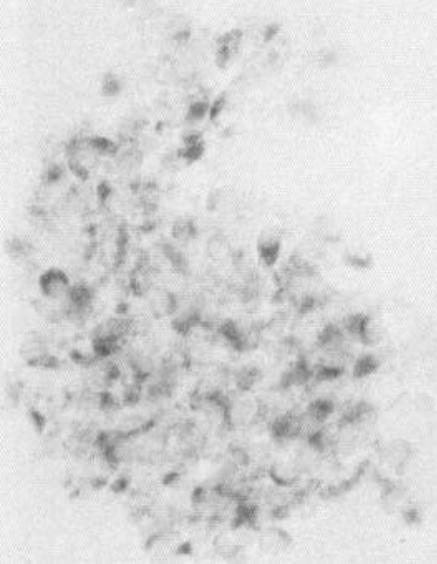

$5-6 d$

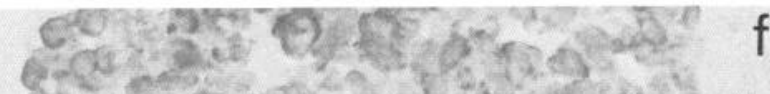

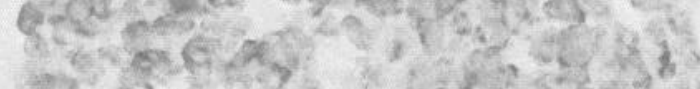

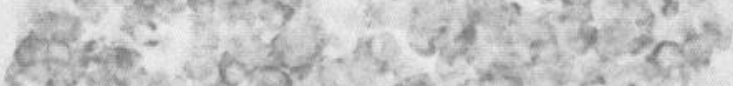
dive $\boldsymbol{x}$,

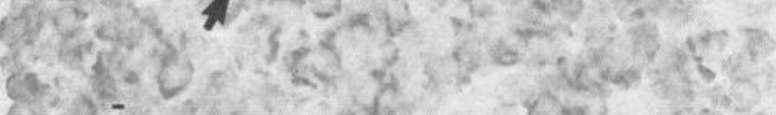

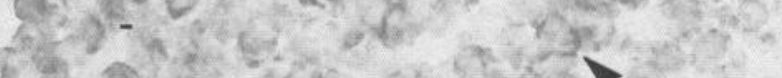
gen

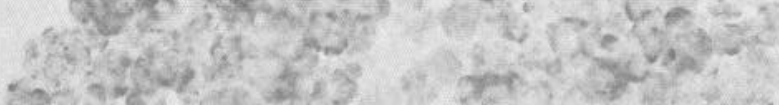

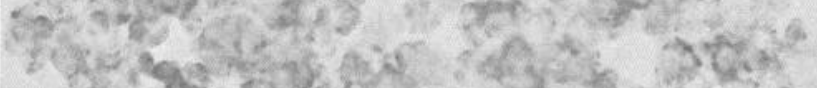
$5-5.5 d$ destas 

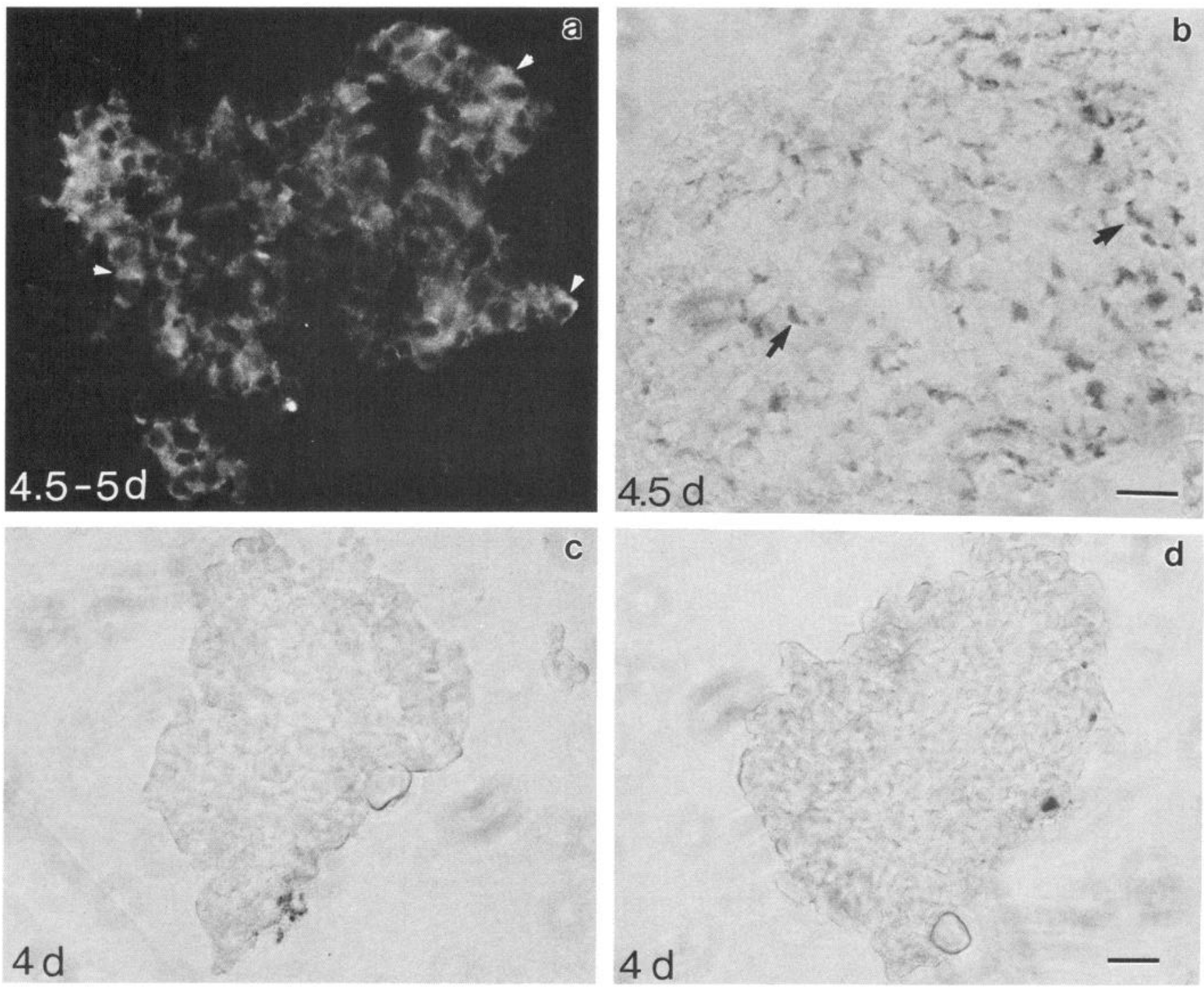

Figure 2. AChR and synaptic vesicle protein immunoreactivity in embryonic ciliary ganglia during the initial phases of synaptogenesis and prior to innervation. Sections of ED 4 and ED 4.5-5 ciliary ganglia were incubated with mAb $35(a, c)$ or anti-SV2 mAb $(b, d)$ followed by the appropriate biotinylated secondary antibody and rhodamine-conjugated avidin $(a)$ or an avidin-biotinylated HRP complex $(b-d)$. Anti-AChR immunolabeling is present in some of the neuron somas (small arrowheads), while other neurons are unlabeled in ED 4.5-5 sections (a). Anti-SV2-stained structures are present immediately adjacent to a part of the surface of some of the neurons (arrows) in ED 4.5 sections $(b)$. No anti-AChR (c) and no antiSV2 (d) labeling is detected in ED 4 sections. Scale bars: $a$ and $b, 20 \mu \mathrm{m} ; c$ and $d, 16 \mu \mathrm{m}$.

by detergent treatment and then incubated with $\mathrm{mAb} 35$ for the labeling of internal AChRs. To detect bound $\mathrm{mAb} 35$, ganglia were incubated with a biotinylated secondary antibody followed by an avidin-biotinylated HRP complex, reacted for peroxidase activity, and examined with the electron microscope.
The distribution of AChRs in both internal and surface pools of ED 11 chick ciliary ganglion neurons resembled the pattern previously observed in older embryonic and newly hatched chick neurons (Jacob et al., 1984, 1986; Jacob and Berg, 1988). Within the ED 11 neurons, substantial amounts of AChRs were present

Figure 1. AChR and synaptic vesicle protein immunoreactivity in embryonic ciliary ganglia at early and late stages of synaptogenesis. Sections of embryonic ciliary ganglia were incubated with $\mathrm{mAb} 35(a, c, e)$ or anti-SV $2 \mathrm{mAb}(b, d, f)$ to detect AChRs or synaptic vesicle proteins, respectively. The bound $\mathrm{mAbs}$ were detected by using biotinylated secondary antibodies followed by rhodamine-conjugated avidin $(a, b)$ or an avidin-biotinylated HRP complex $(c-f)$. HRP staining was used preferentially for the anti-SV2 immunolabeling of sections at early developmental stages because it resulted in reduced levels of nonspecific background staining. Intense AChR labeling is present in all of the neuron somas in ED 13 ciliary ganglion sections $(a)$ and in most of the neuron somas in ED 7-8 ganglion sections $(c)$. Neuronal nuclei and processes are not labeled. A thin patch of antiSV2 $\mathrm{mAb}$ labeling is present immediately adjacent to a portion of the surface of almost every neuron (arrows) in both ED 12 (b) and ED 8 (d) sections. Many of the neuron somas in ED 5-6 sections $(e)$ have anti-AChR mAb labeling, and some of the neurons are heavily labeled. Anti-SV2 staining is present on a portion of the surface of many of the neurons (arrows) in ED 5-5.5 sections ( $f$ ). The ED 5-6 tissue section in $e$ is smaller than the section in $f$ because it was taken farther away from the midline of the ganglion, which is a sphere. Scale bars: $a, 29 \mu \mathrm{m} ; b-f, 20 \mu \mathrm{m}$. 


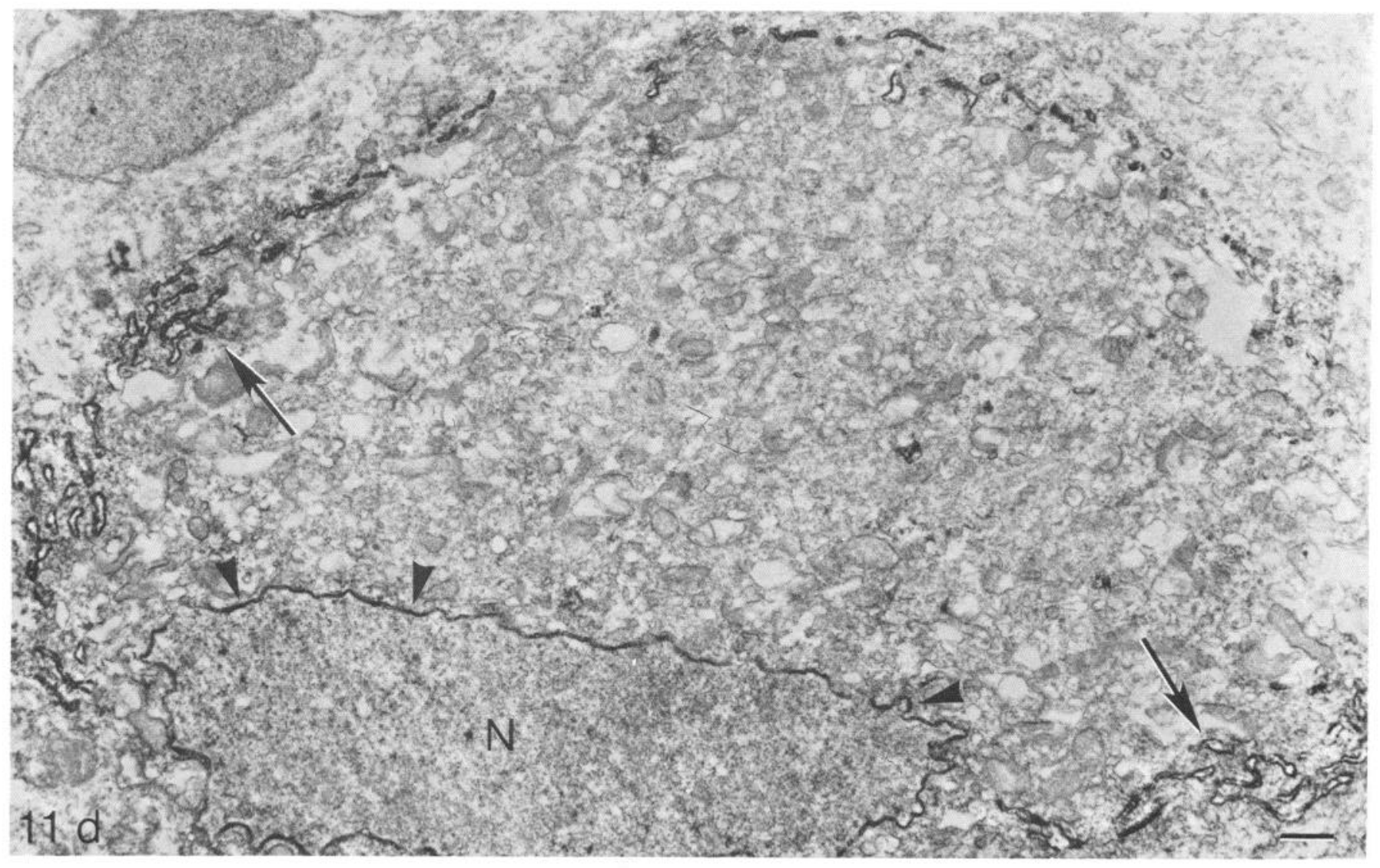

Figure 3. Ultrastructural distribution of intracellular AChRs in ED 11 ciliary ganglion neurons. Ciliary ganglia from ED 11 chicks were lightly fixed, cut into halves, permeabilized with saponin, incubated with mAb 35 followed by a biotinylated secondary antibody and an avidin-biotinylated HRP complex, and reacted for peroxidase activity. Most of the label is present on the Nissl substance or RER, which is concentrated in a layer around the ciliary cell circumference at this stage of development (arrows). A few labeled vesicles and individual cisternae of RER are scattered throughout the cytoplasm of the cell. Portions of the nuclear envelope are also labeled, with HRP reaction product filling the perinuclear cisterna at these sites (arrowheads). The nucleus itself $(N)$ is not labeled, and neither are the mitochondria, free ribosomes, or polysomes. Scale bar, $0.6 \mu \mathrm{m}$.

(Fig. 3). Most of the intracellular labeling was localized on the Nissl bodies or rough endoplasmic reticulum (RER). Reaction product was also present on portions of the nuclear envelope. In neurons as well as in other cell types, the perinuclear cisterna is continuous in several places with the cisternae of the RER, and occasionally ribosomes can be observed to be associated with portions of the outer membrane of the nuclear envelope (Peters et al., 1976; Jacob et al., 1986; Alberts et al., 1989). In addition, some Golgi complexes and a few vesicles, multivesicular bodies, and smooth-membraned vacuoles were labeled. These organelles are known to function in the biosynthesis, processing, and transport of integral plasma membrane proteins. No other labeling was present in the neurons, and no other cell types were labeled in the ganglion.

On the surface of the ED 11 ciliary ganglion neurons, AChRs were predominantly localized in the specialized synaptic membrane. Labeled synapses were present both on the smooth portion of the cell soma and on the short processes or pseudodendrites that emerge from the postsynaptic cell in the region of innervation (Fig. 4a). Synapses on the neurons are characterized by a thickening and parallel arrangement of the pre- and postsynaptic membranes, a widened synaptic cleft, an enhanced postsynaptic density, and an accumulation of synaptic vesicles adjacent to the presynaptic membrane (De Lorenzo, 1960; Hess,
1965; Landmesser and Pilar, 1972). Deposits of HRP reaction product filled the synaptic clefts but did not extend along the surface beyond the specialized synaptic membrane. In addition to the postsynaptic membrane, the only other region on the neuron surface that was labeled were small portions of the plasma membrane of the numerous pseudodendrites (Fig. $4 b$ ). No other cell types in the ganglion were labeled.

In ED 7-7.5 ciliary ganglion neurons, AChRs were also present in both internal and surface pools. Within the neurons, dense deposits of HRP reaction product were predominantly associated with the ribosome-studded membranes of the RER cisternae (Fig. $5 a$ ). In many of the neurons, portions of the nuclear envelope were heavily labeled as well, and a few labeled Golgi complexes, vesicles, smooth-membraned vacuoles, and multivesicular bodies were present in the cytoplasm. On the surface of the neurons, the bulk of the HRP reaction product was associated with the specialized synaptic membrane (Fig. $5 b$ ). The labeling usually filled the clefts but did not extend beyond the specialized synaptic contact zones in the regions of pre- and postganglionic cell apposition. Occasionally, in the extrasynaptic regions of the neuron surface, small patches of reaction product were present on a portion of the cell soma adjacent to a process or on small portions of the pseudodendrite surface membrane. 

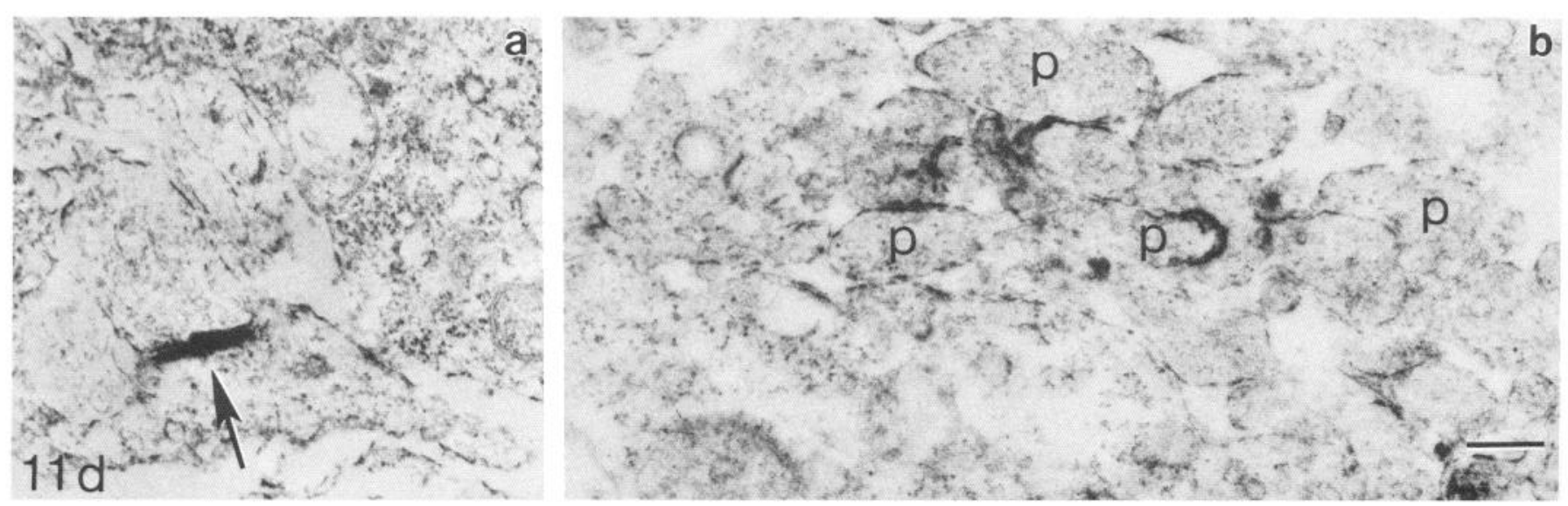

Figure 4. Ultrastructural distribution of AChRs on the surface of ED 11 ciliary ganglion neurons. Freshly dissected, unfixed ED 11 ciliary ganglia were cut into halves, incubated with $\mathrm{mAb} 35$, rinsed, fixed, rinsed, and processed for detection of antibody binding by electron microscopy as described in Figure 3. Surface labeling is predominantly associated with the specialized synaptic membrane of the neurons $(a)$. Dense deposits of HRP reaction product fill the cleft along almost the entire length of the synapse (arrow) present on a process emerging from the postsynaptic ciliary neuron. The labeling does not extend along the surface beyond the specialized synaptic membrane. HRP reaction product is also associated with a noninnervated portion of the surface membrane of the numerous small processes or pseudodendrites $(p)$ that emerge from the postsynaptic neuron (b). Most of the surface membrane of the pseudodendrites is not labeled. Scale bar, $0.3 \mu \mathrm{m}$ for $a$ and $b$.

In ED 4.5 ciliary ganglion neurons, the stage at which synapses were first detected in the ganglion, low levels of $\mathrm{AChR}$ labeling were present in some neurons, while most neurons had no reaction product. In the labeled neurons, AChRs were present in intracellular and surface pools in essentially the same localization as observed in older embryos. Again, most of the intracellular reaction product deposits were associated with the RER. The few labeled RER cisternae were scattered throughout the thin rim of cytoplasm surrounding the neuronal nuclei. In many of these neurons, a small patch of the nuclear envelope was labeled as well. A few neurons, however, were heavily labeled, containing dense deposits of HRP reaction product on cisternae of the RER and on several small patches of the nuclear envelope (Fig. 6a). As for surface labeling, small amounts of reaction product were present on a few neurons. Most of the labeling was associated with the specialized postsynaptic membrane of immature synapses (Fig. 6 b). Immature synapses were identified by the presence of a parallel arrangement of the pre- and postsynaptic membranes, an enhanced postsynaptic density, and the presence of a few pleomorphic, clear vesicles in the presynaptic terminal. In a few of the synapses, the synaptic cleft was widened, and the pre- and postsynaptic membranes were thickened. Immature synapses were located both on the smooth portion of the cell soma and on the processes emerging from the post-
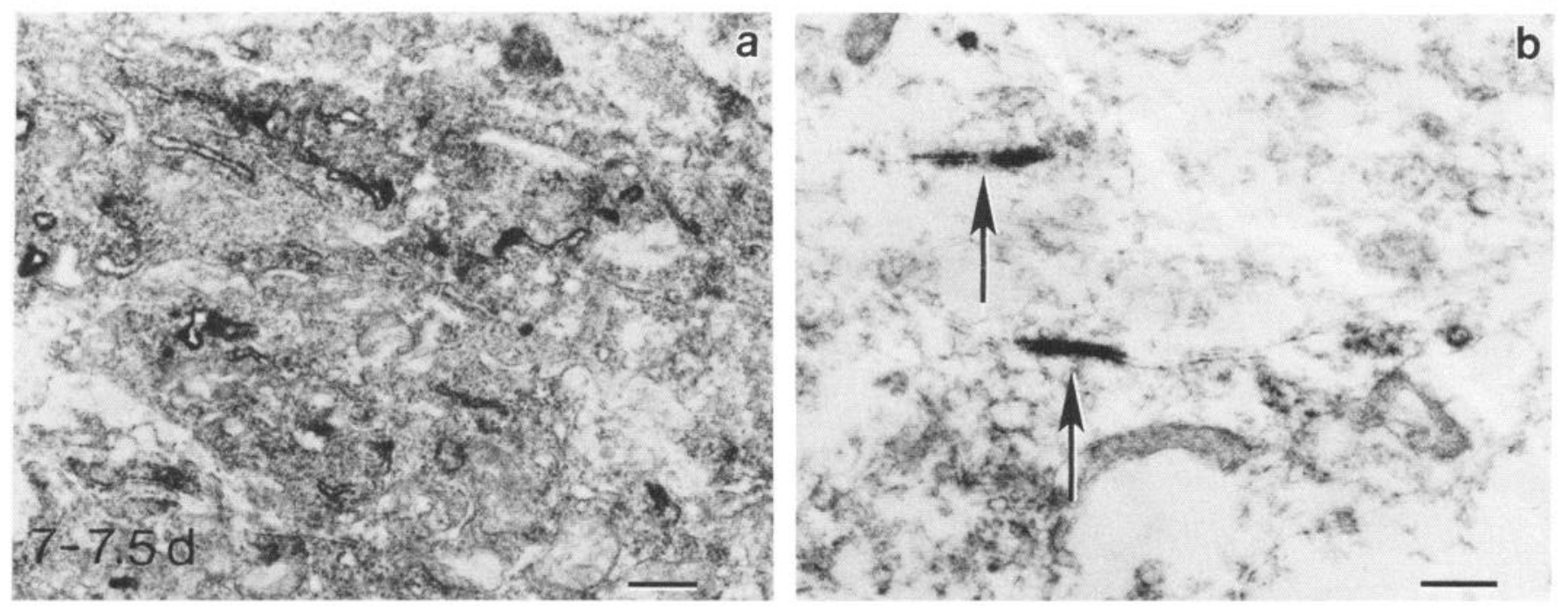

Figure 5. Ultrastructural distribution of AChRs in internal and surface pools of ED 7-7.5 ciliary ganglion neurons. Ciliary ganglia from ED 77.5 chicks were processed for the labeling of internal and surface AChRs as described in Figures 3 and 4, respectively. Most of the intracellular labeling is associated with individual RER cisternae, which are scattered throughout the cytoplasm of the neurons at this stage of development $(a)$. Unlabeled RER cisternae are also present. Most of the surface labeling is associated with the specialized synaptic membrane of the neurons $(b)$. HRP reaction product fills the clefts along almost the entire length of the synapses (arrows) present on the surface of two processes emerging from the postsynaptic neuron. The reaction product deposits do not extend beyond the specialized synaptic membranes on the neuron surface. Scale bars: $a, 0.3 \mu \mathrm{m} ; b, 0.5 \mu \mathrm{m}$. 

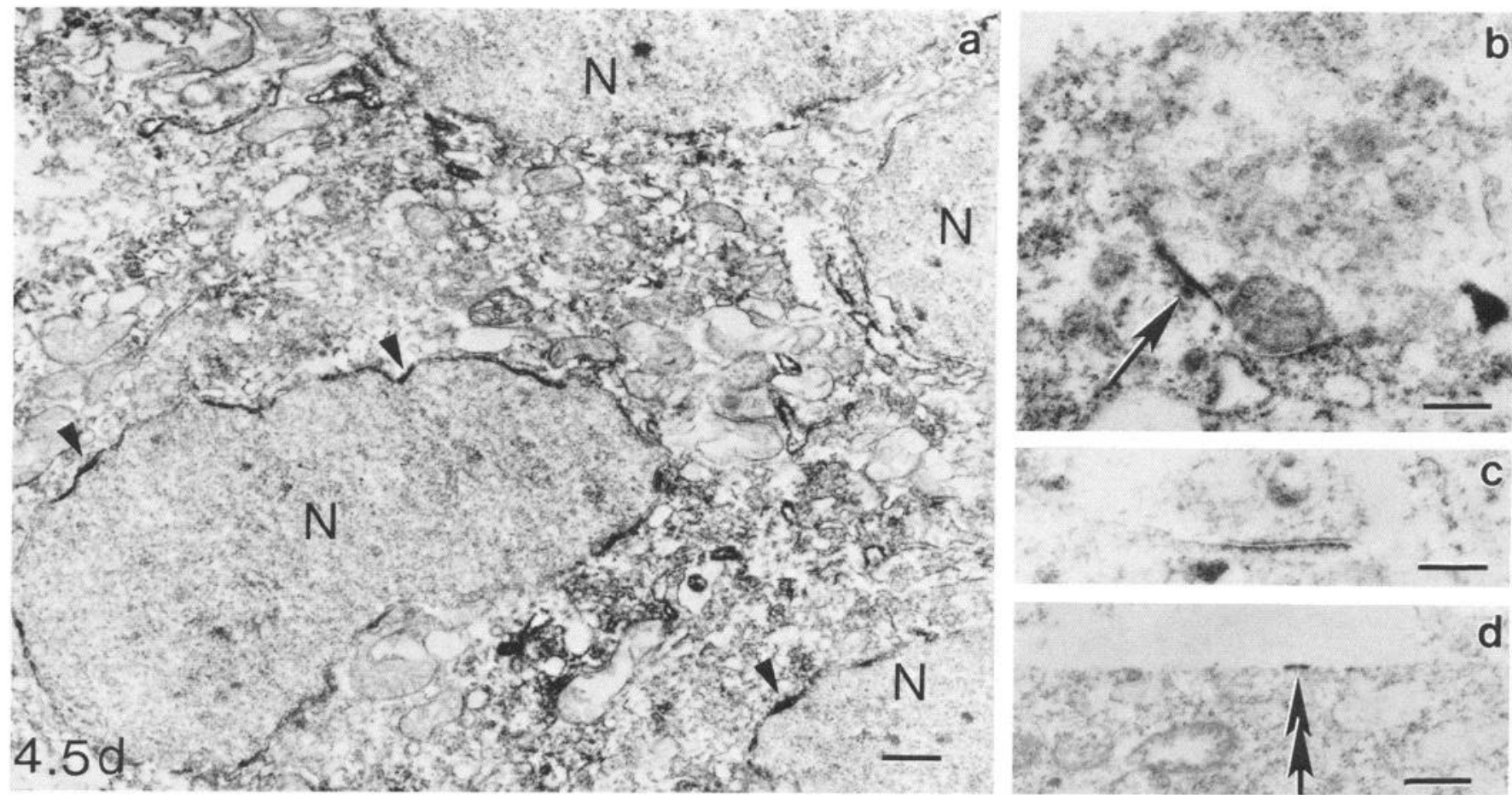

Figure 6. Ultrastructural distribution of AChRs in internal and surface pools of ED 4.5 ciliary ganglion neurons. Ciliary ganglia from ED 4.5 chicks were processed for the labeling of internal and surface AChRs as described in Figures 3 and 4, respectively, except that the ganglia were not cut into halves. Within the few heavily labeled neurons present in the ganglion $(a)$, dense deposits of HRP reaction product are associated with the individual RER cisternae, which are scattered throughout the thin rim of cytoplasm surrounding the neuronal nuclei $(N)$. Small patches of the nuclear envelope are also heavily labeled (arrowheads). Reaction product is present on the surface of a few neurons, as well, being predominantly associated with the specialized synaptic membrane of immature synapses $(b)$. HRP labeling extends along the entire length of the specialized postsynaptic membrane (arrow) present on the smooth portion of the neuron surface. The reaction product does not fill the cleft of the immature synapse and does not extend beyond the specialized synaptic area. An unstained synapse is included for comparison, demonstrating the degree of inherent density associated with the specialized postsynaptic membrane of ED 4.5 neurons $(c)$. On the labeled neuron surface, small patches of reaction product are also occasionally present in extrasynaptic regions (double-headed arrow, $d$ ). This portion of the neuron surface appears to be adjacent to a large open space. Such spaces may have been generated by damage to fine cellular structures during the processing of the tissue required for mAb 35 labeling. Scale bars: $a$ and $d, 0.5 \mu \mathrm{m} ; b$ and $c, 0.3 \mu \mathrm{m}$.

synaptic cell. At the labeled synapses, HRP reaction product deposits only extended along the length of specialized postsynaptic membrane. The reaction product did not fill the clefts of the immature synapses. Occasionally, small patches of labeling were present in extrasynaptic regions of the neuron surface, as well. The labeled patches of plasma membrane were localized both at sites of cell-cell contact, including soma-process and process-process areas, and at uncontacted regions of the neuron surface (Fig. $6 c$ ).

In ED 3.5-4 ciliary ganglion neurons, little anti-AChR immunolabeling was present. The majority of the neurons were unlabeled. In the relatively rare neurons that were labeled, only one or two deposits of HRP reaction product were observed. The labeling was associated with a membranous structure that may be an RER cisterna and with a small patch of the nuclear envelope (Fig. 7). No labeling was detected on the surface of the neurons.

In all cases, with the possible exception of the ED 3.5-4 neurons, the surface and intracellular labeling is likely to represent specific binding of mAb 35 to AChRs. Substitution of nonimmune rat serum for mAb 35 at an equivalent concentration of immunoglobulin did not result in significant labeling of the neurons. On rare occasions, a deposit of HRP reaction product was observed in neurons incubated with nonimmune serum, usually in regions where the tissue was disrupted. The overall lack of staining in control ganglion neurons resembles the spec- ificity of mAb 35 binding observed in older embryonic and newly hatched chick ciliary ganglion neurons (Jacob et al., 1986; Jacob and Berg, 1988).

\section{Discussion}

The major findings reported here are that synapse formation begins as early as ED 4.5 in the chick ciliary ganglion and that there is a large increase in AChR levels in the neurons during the period of synapse formation in the ganglion (Fig. 8). Prior to innervation, few AChRs are present in intracellular pools, and no AChRs can be detected on the surface of the neurons. The results suggest that signals from the presynaptic input play an important role in the induction of AChR expression in the neurons.

Morphologically specialized, immature synapses were identified on the surface of a few ganglionic neurons at ED 4.5 (St 24) by using light microscopy after immunocytochemical labeling with anti-SV2, an $\mathrm{mAb}$ to a transmembrane glycoprotein that is present in synaptic vesicles of all neurons examined (Buckley and Kelly, 1985), and by using ultrastructural analysis. Previously, ED 5 (St 26.5) was reported to be the earliest time at which synaptic transmission could be detected in the ganglion using extracellular recording techniques (Landmesser and Pilar, 1972). Either the morphologically specialized, immature synapses are not functional at ED 4.5, or the evoked response of the few synapses present is too small to be detected by extra- 


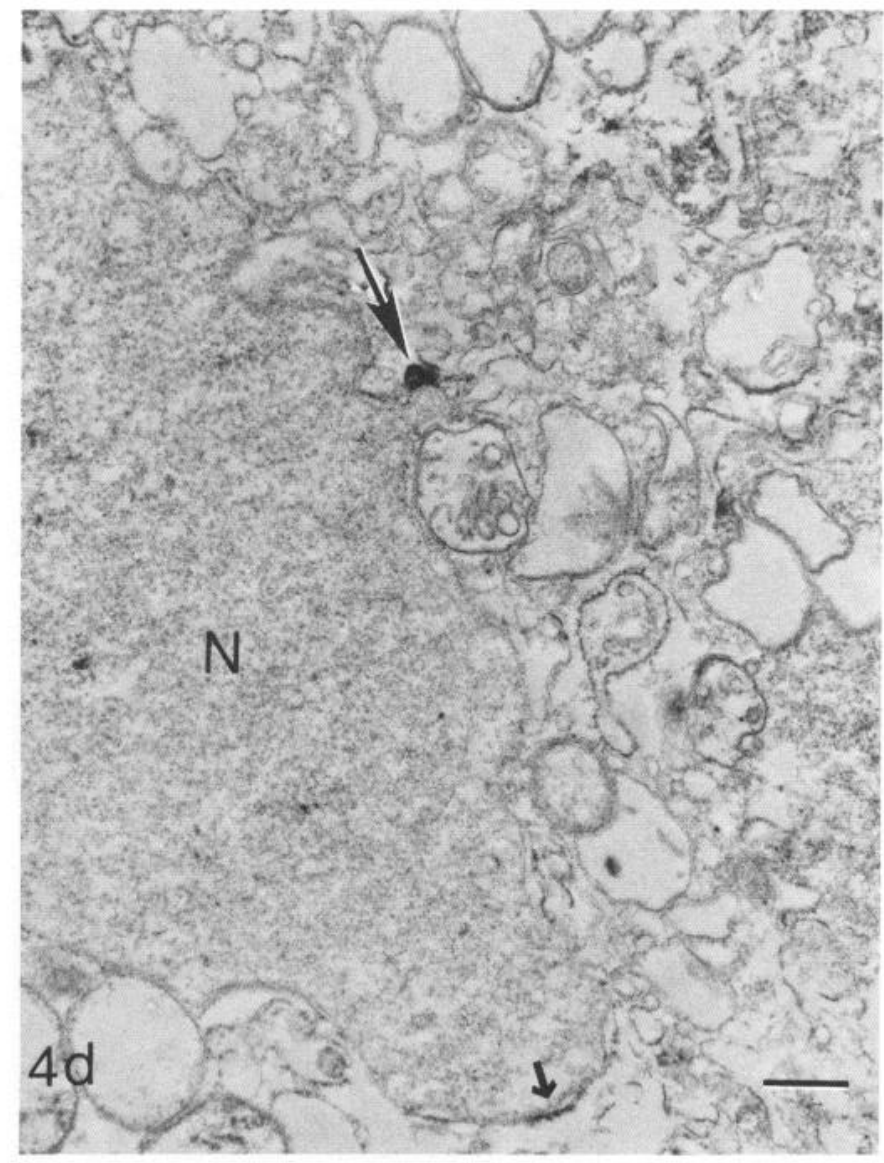

Figure 7. Ultrastructural distribution of intracellular AChRs in ED 4 ciliary ganglion neurons. Ciliary ganglia from ED 4 chicks were processed for the labeling of internal AChRs as described in Figure 3, except that the ganglia were not cut into halves. Within one of the neurons containing the greatest amount of labeling observed in the cells at this stage of development, reaction product is associated with a membranous structure that may be an RER cisterna (large arrow) and with a small patch of the nuclear envelope (small arrow). No other labeling is present in the neuron. $N$, nucleus. Scale bar, $0.5 \mu \mathrm{m}$. cellular recording techniques. In either case, the presence of synapses on a few neurons at ED 4.5 demonstrates that signals from the presynaptic input could be influencing $\mathrm{AChR}$ expression in the neurons at this early stage.

Prior to the period of synapse formation, no anti-AChR immunolabeling was observed in the neurons at the light microscopic level. At the ultrastructural level, a very small number of the ED 3.5-4 neurons had one or two deposits of HRP reaction product. The labeling was on an organelle that could be an RER cisterna and on a small patch of the nuclear envelope. Reaction product at these sites could represent the synthesis of limited amounts of AChRs. These organelles are known to function in the biosynthesis of integral plasma membrane proteins, and internal AChRs of chick ciliary ganglion neurons are integral membrane components that have a number of biochemical properties in common with surface AChRs (Smith et al., 1985; Stollberg and Berg, 1987). Alternatively, the low levels of labeling could be due to the nonspecific binding of reagents, particularly following the disruption of cellular membranes caused by saponin treatment. Similar levels of nonspecific staining have been observed infrequently in ciliary ganglion neurons incubated with nonimmune rat serum in place of $\mathrm{mAb} 35$, usually in areas where the tissue is disrupted. At present, it is not possible to distinguish between these two possibilities.

Later in development, when synapses were detected on a few neurons in the ganglion, substantial levels of AChRs appeared in both intracellular and surface pools of a few neurons, as well. Within the labeled ED 4.5 neurons, reaction product was predominantly associated with the RER and portions of the nuclear envelope. It is not known, however, whether intense anti-AChR immunolabeling occurs in only those neurons receiving synaptic contacts. Such an analysis would require serial reconstruction of individual labeled and unlabeled neurons at the ultrastructural level to determine whether small immature synapses exist on any portion of the neuron surface. At the light microscopic level, a greater number of the ED 4.5-5 neurons had anti-SV2stained structures immediately adjacent to their surface as com-

\section{Acetylcholine Receptor Expression in the Developing Chick Ciliary Ganglion}

$--\frac{\text { AChRs - Internal Sites }}{\text { AChRs - Surface Sites }}$

Innervation

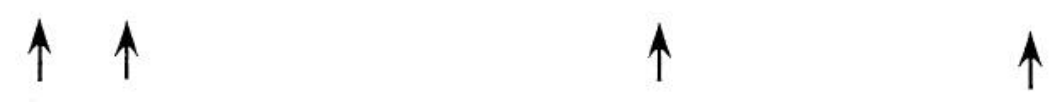

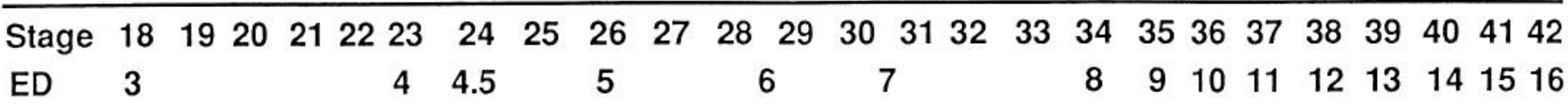

Figure 8. Time course of synapse formation and AChR expression in developing chick ciliary ganglion neurons. ED 4.5 is the earliest time at which synapses were identified in the ganglion (see Figs. 2, 6). AChRs are present on the surface of ED 4.5 neurons (see Fig. 6) but are not detectable on the surface of neurons at ED 4. AChRs are present within some neurons at ED 4.5 (see Figs. 2, 6), while few AChRs are present within ED 4 neurons (represented by the broken line; see Figs. 2, 7). At older stages of development, AChRs are present in both internal and surface pools of the neurons (see Figs. 1, 3-5). The arrows indicate the developmental stages at which the ultrastructural distribution of AChRs was investigated. 
pared to the number of neurons expressing AChRs (Table 1). The proportion of the anti-SV2-labeled structures that represents immature synapses is not known due to the presence of growth cones emanating from the ciliary ganglion neurons at this stage.

As the neurons developed and synapses continued to form and mature, there were increases in the number of anti-AChRimmunolabeled neurons, and the values were similar to the number of neurons having anti-SV2-stained structures on their surface. In addition, the levels of internal and surface AChR labeling increased in the neurons. More RER cisternae and Nissl bodies formed in the cytoplasm as the neurons grew larger, and most of the RER was labeled. On the neuron surface, the deposits of HRP reaction product increased in amount at the specialized postsynaptic membrane such that, from ED 7-7.5 on, the deposits filled the synaptic cleft. The extent of extrasynaptic labeling appeared to increase as well from ED 4.5 to ED 11. Consistent with these results, the highest levels of AChRs per ganglionic protein have been reported to occur between ED 12 and 18 , when synapses are maturing and being consolidated on the neurons (Smith et al., 1985).

In the present study, more of the reaction product was associated with the neuron interior than with the neuron surface at all ages examined, and all of the intracellular labeling was associated with organelles known to function in the biosynthesis, processing, and transport of integral plasma membrane proteins. The proportion of the internal sites that is destined for the cell surface is unknown at these developmental stages. Studies in cell culture indicate that two-thirds of the total AChRs associated with chick ciliary ganglion neurons are intracellular and that about $5 \%$ of the internal receptors are transported to the cell surface (Stollberg and Berg, 1987). The studies were done on ED 8 ciliary ganglion neurons that were maintained in culture for $4 \mathrm{~d}$. The proportion of the receptors that are transported to the cell surface may differ in neurons in situ and in neurons at earlier stages of development.

On the developing neuron surface, no AChRs were detected prior to innervation (ED 3.5-4), and only small patches of AChR labeling were observed in extrasynaptic regions during the period of synapse formation (beginning at ED 4.5). On developing myotubes and myotomes in situ, AChRs are diffusely distributed along the entire surface prior to innervation and slowly decline in extrajunctional regions over a period of several days following innervation as determined by autoradiographic labeling methods (Bevan and Steinbach, 1977; Burden, 1977; Harris, 1981; Meiniel and Bourgeois, 1982; Chow and Cohen, 1983). Further, high concentrations of AChRs extend beyond the specialized postsynaptic membrane at newly formed synapses on muscle (Jacob and Lentz, 1979), but not on neurons as shown by using HRP labeling techniques. Either AChRs are not localized at these sites on developing neurons, or AChRs are present at densities below the limits of detection of the immunocytochemical labeling methods employed. The latter may be true even though a highly sensitive immunoperoxidase labeling method, $\mathrm{mAb} 35$ followed by a biotinylated secondary antibody and an avidin DH-biotinylated HRP H complex, was used to achieve an amplification of the signal. HRP-labeling methods that provide less amplification (i.e., HRP-conjugated $\mathrm{mAb} 35$ and $\mathrm{mAb} 35$ followed by an HRP-conjugated secondary antibody) detected synaptic AChRs on late-stage embryo and newly hatched chick ciliary ganglion neurons (Jacob et al., 1984, 1986; Jacob and Berg, 1988), which are estimated to be present at 600 sites $/ \mu \mathrm{m}^{2}$ (Loring and Zigmond, 1987). On embryonic chick skeletal muscle, HRP directly coupled to the primary ligand detected junctional but not extrajunctional AChRs (Jacob and Lentz, 1979), which are estimated to be present at $10^{4}$ and 250 sites $/ \mu \mathrm{m}^{2}$, respectively (Burden, 1977). In the present study, small patches of AChR labcling wcrc detected in extrasynaptic regions of the developing neuron surface. The density of AChRs at these sites is not known. The amount of HRP reaction product cannot be quantitatively measured, and reaction conditions were chosen to give readily identifiable reaction product, rather than being adjusted to achieve linearity between receptor number and the formation of reaction precipitate. Other methods must be applied to quantitate AChR levels in synaptic and extrasynaptic regions of the developing neuron surface, and such methods may be sensitive enough to determine whether low levels of AChRs are present prior to innervation.

The large increase in both internal and surface AChR levels in the neurons at the time of innervation suggests that innervation influences $A C h R$ expression in neurons. This conclusion is also supported by the findings of other recent studies. Innervation of embryonic chick sympathetic ganglion neurons in culture by the appropriate preganglionic tissue, the dorsal spinal cord, results in a 10-fold increase in ACh sensitivity as compared to the levels on neurons grown alone (Role, 1988). Growth of the neurons in the presence of preganglionic neuronal, but not non-neuronal cell-conditioned medium, produces a fourfold increase in ACh sensitivity, suggesting that the innervationinduced enhancement is mediated by neurally derived soluble factors. Electrical activity is not involved because the chronic blockade of synaptic transmission by $d$-tubocurarine does not prevent the increase in $\mathrm{ACh}$ sensitivity induced by innervation. Patch-clamp analysis of dissociated sympathetic neurons at very early and late stages of synapse formation suggests that the increase in ACh sensitivity on innervated neurons is likely due to changes in the single-channel properties and possibly the subtype of AChRs expressed (Moss et al., 1989). Similar studies of freshly dissociated chick ciliary ganglion neurons reveal developmental changes in the relative abundancc and kinetics of AChR conductance classes, as well as fourfold increases in both the ACh response per unit membrane area and the average density of surface AChRs (including both functional and silent receptors) on the neurons (Margiotta and Gurantz, 1989). These changes in AChR properties occur during a developmental period of synapse maturation, ranging from ED 8 to ED 16. Further, in the developing chick lateral spiriform nucleus, AChR $\alpha 2$ transcripts reach detectable levels at a time that coincides with the appearance of cholinergic afferents as determined by using in situ hybridization and immunohistochemical staining (Daubas et al., 1990). The accumulation represents a five- to sixfold increase in $\alpha 2$ transcript levels as quantitated using the polymerase chain reaction. Similarly, in developing chick ciliary ganglion neurons, $\mathrm{AChR} \alpha 3$ transcript is not detectable at stages prior to innervation, while the levels increase during the period of synapse formation as determined in preliminary in situ hybridization studies (M. H. Jacob, unpublished observations). Altogether, the evidence suggests that the establishment of innervation influences AChR mRNA levels and the number and properties of AChRs expressed in developing neurons. It will be necessary to demonstrate, however, that the increases in AChR and AChR mRNA levels and the changes in AChR channel types are caused by innervation, as opposed to being the result of other cell-cell interactions, or the result of an intrinsic 
developmental program. Along these lines, the transient increase in non- $\alpha(\beta 2)$ AChR mRNA levels that normally occurs in chick optic tectum neurons at the time of retinotectal synaptogenesis was not observed to occur in tectal neurons of eyeless embryos (Matter et al., 1990). Similarly, chick ciliary ganglion neurons developing in situ in the absence of the preganglionic tissue have either no or very low levels of anti$\Lambda$ ChR immunolabeling as compared to control neurons at the light microscopic level (L. Arenella and M. H. Jacob, unpublished observations). These recent findings demonstrate that signals from the presynaptic neurons regulate $A C h R$ and $A C h R$ mRNA levels in developing neurons.

A number of regulatory principles have been emerging from studies of the effects of innervation on AChR and AChR mRNA levels in multinucleated and mononucleated muscle cells, and these principles may apply to neurons, as well. In muscle, innervation influences AChR gene transcript levels and the number, distribution, metabolic stability, channel kinetics, and subtype of AChRs expressed (Fambrough, 1979; Salpeter, 1987; Schuetze and Role, 1987; Brehm and Henderson, 1988; Gu and Hall, 1988; Fumagalli et al., 1990). For example, innervation of mammalian muscle, for even short periods of time, induces the expression of $\epsilon$-subunit mRNA in the end-plate region, suggesting that a locally acting neurally derived signal is responsible for the induction (Brenner et al., 1990). This innervation-induced change in AChR gene expression results in a change in the subunit composition [the mature adult form of the receptor $\left(\alpha_{2} \beta \epsilon \delta\right)$ replaces the embryonic form $\left.\left(\alpha_{2} \beta \gamma \delta\right)\right]$ and in the singlechannel properties of AChRs on the cell surface (Mishina et al., 1986; Gu and Hall, 1988; Witzemann et al., 1989). Further, a number of neurally derived factors, including AChR-inducing activity (ARIA), calcitonin gene-related peptide, and ascorbic acid, increase surface AChR and AChR $\alpha$-subunit mRNA levels in muscle (Fontaine et al., 1987; Harris et al., 1988, 1989; Horovitz et al., 1989; Bursztajn et al., 1990). In contrast, motoneuron-driven electrical activity downregulates extrajunctional AChR and AChR mRNA levels that have been enhanced after denervation of multinucleated myofibers (Lomo and Westgaard, 1975; Reiness and Hall, 1977; Linden and Fambrough, 1979; Goldman et al., 1988). In developing mononucleated Xenopus myotomal muscle cells, however, activity does not influence AChR mRNA levels (Baldwin et al., 1988). Altogether, the data suggest that $A C h R$ gene expression is regulated differently by neurally derived factors and by electrical activity in muscle cells. In the junctional region of multinucleated myofibers and in mononucleated muscle cells, the positive effects of neurally derived factors predominate over the repressive effects of electrical activity, resulting in the activation of $\mathrm{AChR}$ gene expression in nearby nuclei. The neurally derived factors have a limited sphere of influence, however, and motoneuron-driven electrical activity represses AChR gene expression in nuclei present in extrajunctional regions of the myofiber (Baldwin et al., 1988; Fontaine and Changeux, 1989). In neurons, which are mononucleated, AChR gene expression may be regulated in a similar way, with synaptic factors exerting the predominant effect. To establish that this is true, the regulatory effects of both neurally derived factors and electrical activity on AChR gene expression in neurons must be compared.

In summary, few AChRs are present in intracellular pools and no AChRs can be detected on the surface of chick ciliary ganglion neurons prior to innervation. Substantial levels of AChRs appear in both surface and intracellular pools of the neurons during the period of synapse formation in the ganglion. Based on these findings and all of the other studies, it seems likely that preganglionic tissue-derived factors play a major role in the regulation of $A C h R$ and AChR mRNA levels in neurons.

\section{References}

Alberts B, Bray D, Lewis J, Raff M, Roberts K, Watson JD (1989) Intracellular sorting and the maintenance of cellular compartments. In: Molecular biology of the cell, pp 421-422. New York: Garland.

Baldwin TJ, Yoshihara CM, Blackmer K, Kintner CR, Burden SJ (1988) Regulation of acetylcholine receptor transcript expression during development in Xenopus laevis. J Cell Biol 106:469-478.

Bevan S, Steinbach JH (1977) The distribution of $\alpha$-bungarotoxin binding sites on mammalian skeletal muscle developing in vivo. J Physiol (Lond) 267:195-213.

Boyd RT, Jacob MH, Couturier S, Ballivet M, Berg DK (1988) Expression and regulation of neuronal acetylcholine receptor mRNA in chick ciliary ganglia. Neuron 1:495-502.

Brehm P, Henderson LP (1988) Regulation of acetylcholine receptor channel function during development of skeletal muscle. Dev Biol 129:1-11.

Brenner HR, Witzemann V, Sakmann B (1990) Imprinting of acetylcholine receptor messenger RNA accumulation in mammalian neuromuscular synapses. Nature 344:544-547.

Buckley K, Kelly RB (1985) Identification of a transmembrane glycoprotein specific for secretory vesicles of neural and endocrine cells. J Cell Biol 100:1284-1294.

Burden S (1977) Development of the neuromuscular junction in the chick embryo: the number, distribution, and stability of acetylcholine receptors. Dev Biol 57:317-329.

Bursztajn S, Berman SA, Gilbert W (1990) Factors released by ciliary neurons and spinal cord explants induce acetylcholine receptor $\mathrm{mRNA}$ expression in cultured muscle cells. J Neurobiol 21:387-399.

Chow I, Cohen MW (1983) Developmental changes in the distribution of acetylcholine receptors in the myotomcs of Xenopus laevis. J Physiol (Lond) 339:553-571.

Daubas P, Devillers-Thiéry A, Geoffroy B, Martinez S, Bessis A, Changeux JP (1990) Differential expression of the neuronal acetylcholine receptor $\alpha 2$ subunit gene during chick brain development. Neuron 5: 49-60.

De Lorenzo AJ (1960) The fine structure of synapses in the ciliary ganglion of the chick. J Biophys Biochem Cytol 7:31-36.

Dennis MJ, Sargent PB (1979) Loss of extrasynaptic acetylcholine sensitivity upon reinnervation of parasympathetic ganglion cells. J Physiol (Lond) 289:263-275.

Dunn PM, Marshall LM (1985) Lack of nicotinic supersensitivity in frog sympathetic neurones following denervation. J Physiol (Lond) 363:211-225.

Fambrough DM (1979) Control of acetylcholinc receptors in skeletal muscle. Physiol Rev 59:165-227.

Fontaine B, Changeux JP (1989) Localization of nicotinic acetylcholine receptor $\alpha$-subunit transcripts during myogenesis and motor endplate development in the chick. J Cell Biol 108:1025-1037.

Fontaine B, Klarsfeld A, Changeux JP (1987) Calcitonin gene-related peptide and muscle activity regulate acetylcholine receptor $\alpha$-subunit mRNA levels by distinct intracellular pathways. J Cell Biol 105:13371342.

Fumagalli G, Balbi S, Cangiano A, Lomo T (1990) Regulation of turnover and number of acetylcholine receptors at neuromuscular junctions. Neuron 4:563-569.

Goldman D, Brenner HR, Heinemann S (1988) Acetylcholine receptor $\alpha-, \beta-, \gamma-$, and $\delta$-subunit mRNA levels are regulated by muscle activity. Neuron 1:329-333.

Gu Y, Hall Z (1988) Immunological evidence for a change in subunits of the acetylcholine receptor in developing and denervated rat muscle. Neuron 1:117-125.

Halvorsen SW, Berg DK (1987) Affinity labeling of neuronal acetylcholine receptor subunits with an $\alpha$-neurotoxin that blocks receptor function. J Neurosci 7:2547-2555.

Hamburger V, Hamilton HL (1951) A series of normal stages in the development of the chick embryo. J Morphol 88:49-92.

Harris AJ (1981) Embryonic growth and innervation of rat skeletal muscles. III. Neural regulation of junctional and extra-junctional ace- 
tylcholine receptor clusters. Philos Trans R Soc Lond [Biol] 293:287314.

Harris DA, Falls DL, Dill-Devor RM, Fischbach GD (1988) Acetylcholine receptor-inducing factor from chicken brain increases the level of mRNA encoding the receptor $\alpha$ subunit. Proc Natl Acad Sci USA 85:1983-1987.

Ilarris DA, Falls DL, Fischbach GD (1989) Differential activation of myotube nuclei following exposure to an acetylcholine receptor-inducing factor. Nature 337:173-176.

Hess A (1965) Developmental changes in the structure of the synapse on the myelinated cell bodies of the chicken ciliary ganglion. J Cell Biol 25:1-19.

Horovitz O, Knaack D, Podleski TR, Salpeter MM (1989) Acetylcholine receptor $\alpha$-subunit mRNA is increased by ascorbic acid in cloned $\mathrm{L}_{5}$ muscle cells: Northern blot analysis and in situ hybridization. J Cell Biol 108:1823-1832.

Hruschak KA, Friedrich VL Jr, Giacobini E (1982) Synaptogenesis in chick paravertebral sympathetic ganglia: a morphometric analysis. Dev Brain Res 4:229-240.

Jacob M, Lentz TL (1979) Localization of acetylcholine receptors by means of horseradish peroxidase- $\alpha$-bungarotoxin during formation and development of the neuromuscular junction in the chick embryo. J Cell Biol 82:195-211.

Jacob MH, Berg DK (1987) Effects of preganglionic denervation and postganglionic axotomy on acetylcholine receptors in the chick ciliary ganglion. J Cell Biol 105:1847-1854.

Jacob MH, Berg DK (1988) The distribution of acetylcholine receptors in chick ciliary ganglion neurons following disruption of ganglionic connections. J Neurosci 8:3838-3849.

Jacob MH, Berg DK, Lindstrom JM (1984) A shared antigenic determinant between the Electrophorus acetylcholine receptor and a synaptic component on chick ciliary ganglion neurons. Proc Natl Acad Sci USA 81:3223-3227.

Jacob MH, Lindstrom JM, Berg DK (1986) Surface and intracellular distribution of a putative neuronal acetylcholine receptor. J Cell Biol 103:205-214.

Kuffler SW, Dennis MJ, Harris AJ (1971) The development of chemosensitivity in extrasynaptic areas of the neuronal surface after denervation of parasympathetic ganglion cells in the heart of the frog. Proc R Soc Lond [Biol] 177:555-563.

Landmesser L, Pilar G (1972) The onset and development of transmission in the chick ciliary ganglion. J Physiol (Lond) 222:691-713.

Landmesser L, Pilar $G$ (1978) Interactions between neurons and their targets during in vivo synaptogenesis. Fed Proc 37:2016-2022.

Linden DC, Fambrough DM (1979) Biosynthesis and degradation of acetylcholine receptors in rat skeletal muscle. Effects of electrical stimulation. Neuroscience 4:527-538.

Lomo T, Westgaard RH (1975) Control of ACh sensitivity in rat muscle fibers. Cold Spring Harbor Symp Quant Biol 40:263-274.

Loring RH, Zigmond RE (1987) Ultrastructural distribution of ${ }^{125} \mathrm{I}$ toxin $\mathrm{F}$ binding sites on chick ciliary neurons: synaptic localization of a toxin that blocks ganglionic nicotinic receptors. J Neurosci 7: 2153-2162.

Margiotta JF, Gurantz D (1989) Changes in the number, function and regulation of nicotinic acetylcholine receptors during neuronal development. Dev Biol 135:326-339.

Margiotta JF, Berg DK, Dionne VE (1987a) Cyclic AMP regulates the proportion of functional acetylcholine receptors on chicken ciliary ganglion neurons. Proc Natl Acad Sci USA 84:8155-8159.
Margiotta JF, Berg DK, Dionne VE (1987b) The properties and regulation of functional acetylcholine receptors on chick ciliary ganglion neurons. J Neurosci 7:3612-3622.

Marshall LM (1985) Presynaptic control of synaptic channel kinetics in sympathetic neurones. Nature 317:621-623.

Matter JM, Matter-Sadzinski L, Ballivet M (1990) Expression of neuronal nicotinic acetylcholine receptor genes in the developing chick visual system. EMBO J 9:1021-1026.

McEachern AE, Jacob MH, Berg DK (1989) Differential effects of nerve transection on the ACh and GABA receptors of chick ciliary ganglion neurons. J Neurosci 9:3899-3907.

Meiniel R, Bourgeois JP (1982) Appearance and distribution in situ of nicotinic acetylcholine receptors in cervical myotomes of young chick embryos. Anat Embryol 164:349-368.

Mishina M, Takai T, Imoto K, Noda M, Takahashi T, Numa S, Methfessel C, Sakmann B (1986) Molecular distinction between fetal and adult forms of muscle acetylcholine receptor. Nature 321:406-411.

Moss BL, Schuetze SM, Role LW (1989) Functional propertics and developmental regulation of nicotinic acetylcholine receptors on embryonic chicken sympathetic neurons. Neuron 3:597-607.

Peters A, Palay SL, Webster HD (1976) The neuronal cell body. In: The fine structure of the nervous system, pp 50-55. Philadelphia: Saunders.

Reiness CG, Hall ZW (1977) Electrical stimulation of denervated muscles reduces incorporation of methionine into the $\mathrm{ACh}$ receptor. Nature 268:655-657.

Role LW (1988) Neural regulation of acetylcholine sensitivity in embryonic sympathetic neurons. Proc Natl Acad Sci USA 85:28252829.

Salpeter MM (1987) Development and neural control of the neuromuscular junction and of the junctional acetylcholine receptor. In: The vertebrate neuromuscular junction (Salpetcr MM, ed), pp 55115. New York: Liss.

Sargent PB, Bryan GK (1989) Effect of denervation upon acetylcholine receptor number on the surface of cardiac ganglion cells. Soc Neurosci Abstr 15:497.

Sargent PB, Pang DZ (1988) Denervation alters the size, number, and distribution of clusters of acetylcholine receptor-like molecules on frog cardiac ganglion neurons. Neuron 1:877-886.

Schuetze SM, Role LW (1987) Developmental regulation of nicotinic acetylcholine receptors. Annu Rev Neurosci 10:408-457.

Smith MA, Stollberg J, Lindstrom JM, Berg DK (1985) Characterization of a component in chick ciliary ganglia that crossreacts with monoclonal antibodies to muscle and electric organ acetylcholine receptor. J Neurosci 5:2726-2731.

Smith MA, Margiotta JF, Franco A Jr, Lindstrom JM, Bcrg DK (1986) Cholinergic modulation of an acetylcholine receptor-like antigen on the surface of chick ciliary ganglion neurons in cell culture. J Neurosci 6:946-953.

Stollberg J, Berg DK (1987) Neuronal acetylcholine receptors: fate of surface and internal pools in cell culture. J Neurosci 7:1809-1815.

Tzartos SJ, Rand DE, Einarson BL, Lindstrom JM (1981) Mapping of surface structure of Electrophorus acetylcholine receptor using monoclonal antibodies. J Biol Chem 256:8635-8645.

Witzemann V, Barg B, Criado M, Stein E, Sakmann B (1989) Developmental regulation of five subunit specific mRNAs encoding acetylcholine receptor subtypes in rat muscle. FEBS Lett 242:419-424. 